\title{
CAPÍTULO 35: AVALIAÇÃo DE MERCADO E DAS BOAS PRÁTICAS DE MANIPULAÇÃO DE HORTOFRUTÍCOLAS ENTREGUES A DOMICÍLIO EM CAMPOS DOS GOYTACAZES/RJ
}

\section{CHAPTER 35: MARKET EVALUATION AND GOOD HANDLING PRACTICES OF HORTIFRÚTIS DELIVERY IN CAMPOS DOS GOYTACAZES/RJ}

\author{
Lara Poses Mussi ${ }^{1}$; Rosana Maria dos Santos Nani de Miranda ${ }^{2}$; Jaomara Nascimento da Silva ${ }^{3}$; \\ Rafael dos Santos Costa ${ }^{4}$
}

\begin{abstract}
Resumo
O crescimento progressivo de entregas a domicílio (delivery) de hortofrutícolas requer cuidados higiênico-sanitários adequados em toda cadeia produtiva. Logo, o objetivo deste trabalho foi avaliar o nicho de mercado de delivery de hortifrútis em Campos dos Goytacazes/RJ focando na qualidade e segurança dos alimentos. Em 2019, o delivery foi avaliado por uma entrevista estruturada com responsáveis dos 10 hortifrútis, com aplicação do checklist de boas práticas, além de avaliar o perfil e a satisfação dos consumidores finais pelo questionário on-line. Os resultados demonstraram que as boas práticas dos hortifrútis foram satisfatórias nos itens manipuladores, armazenamento e transporte do alimento, entretanto, demais itens precisariam fazer a correção das inadequações. Todos os hortifrútis utilizam redes sociais para marketing; $10 \%$ dos hortifrútis produzem e $90 \%$ compram de fornecedores. O perfil do consumidor prépandemia no serviço delivery varia de 19-81 anos, sendo 54\% na faixa dos 31-50 anos; 38\% possuindo renda acima de 4 salários mínimos; $76 \%$ tem ensino superior e $43 \%$ compram semanalmente. Portanto, o delivery dos hortifrútis no município possibilitou agregar valor aos produtos agrícolas, sendo um diferencial nesse segmento de mercado, e melhorar a distribuição de renda. Ademais, a pesquisa demonstrou satisfação dos consumidores pela qualidade do atendimento, comodidade e praticidade.
\end{abstract}

Palavras-Chave: boas práticas, delivery, gestão, manipulação, perfil do consumidor.

\begin{abstract}
The progressive growth of delivery of fruit and vegetables requires adequate hygienic-sanitary care throughout the production chain. Therefore, the objective of this work was to evaluate the delivery market niche of Hortifrutis in Campos dos Goytacazes/RJ focusing on food quality and safety. In 2019, the delivery was evaluated by a structured interview with the responsible 10 Hortifrutis, with application of the checklist of good practices, in addition to evaluate the profile and satisfaction of final consumers through the online questionnaire. The results demonstrated that the good practices of Hortifrutis were satisfactory in handling items, storage and transportation of food, however, other items would need to correct inadequacies. All the Hortifrutis uses social networks for marketing; $10 \%$ of the Hortifrutis produce and $90 \%$ buy from suppliers. The pre-pandemic consumer profile in the delivery service it varies from 19-81

\footnotetext{
${ }^{1}$ Dra. em Produção Vegetal, UENF, e Técnica em Agronegócios, SENAR, lara_pmw@ homail.com

${ }^{2}$ Graduanda em Agronomia, UENF, e Técnica em Agronegócios, SENAR, ronani.uenf@gmail.com

${ }^{3}$ Dra. em Produção Vegetal, UENF, jaomarasilva@gmail.com

${ }^{4}$ MSc. em Ciência Animal, SIE-RJ, rafaelroyal@yahoo.com.br
} 
years, with $54 \%$ in the range of $31-50$ years; $38 \%$ having an income above 4 minimum wages; $76 \%$ have higher education and $43 \%$ buy weekly. Therefore, delivery of Hortifrutis in the municipality made it possible aggregate value to agricultural products, being a differential in this market segment, and improve income distribution. Furthermore, the survey demonstrated consumer satisfaction with the quality of service, convenience and practicality.

Keywords: good practices, delivery, management, handling, consumer profile.

\section{Introdução}

O nicho de mercado de entregas a domicílio (tele-entrega ou delivery) vem sendo uma estratégia de comercialização das frutas e hortaliças em alguns hortifrútis no município de Campos dos Goytacazes - RJ. Em tempos de globalização, a expansão da utilização das tecnologias inovadoras, como a internet, possibilita o acesso às diversas redes sociais por meio do uso de aplicativos em smartphones (exemplo do WhatsApp), promovendo aos empreendimentos adequações necessárias para atender as novas tendências deste mercado dinâmico e competitivo do agronegócio.

Deste modo, o serviço de entregas a domicílio dos hortifrútis demonstra que os empresários estão atentos às mudanças desse mercado e às demandas da sociedade. Uma característica empreendedora, na qual transforma em realidade uma oportunidade de que frutas e hortaliças possam chegar até o consumidor final sem que o mesmo saia de suas residências (SOUZA; HOLANDA, 2019; LIMA, 2018; MAGALHÃES, 2018; CASTRO, 2016; SEBRAE, 2014).

No entanto, frutas e hortaliças são produtos perecíveis e necessitam de cuidados e tecnologias adequadas na cadeia de comercialização para que sejam entregues ao consumidor com suas características preservadas, a fim de garantir qualidade e segurança alimentar (CHITARRA; CHITARRA, 2005). Dessa forma, a Agência Nacional de Vigilância Sanitária (ANVISA), responsável pela fiscalização e regulamentação de todos os aspectos sanitários do país, estabelece as Boas Práticas para Serviços de Alimentação por meio da Resolução da Diretoria Colegiada (RDC) $N^{o} 216 / 2004$, na qual define que os estabelecimentos devem se adequar para proporcionar essa segurança aos consumidores (BRASIL, 2004).

Segundo a ANVISA, a manipulação de alimentos envolve todas as operações com a matéria-prima, desde a sua obtenção (colheita) até a entrega (preparação, embalagem, armazenamento, transporte, distribuição e exposição à venda). As pessoas que entram em contato direto ou indireto com o alimento em todas essas operações são reconhecidas como manipuladores (BRASIL, 2004). Sendo assim, a qualidade das frutas, legumes e verduras é 
iniciada no campo pelos produtores com as boas práticas agrícolas, mas tem de ser mantida ao longo da cadeia de abastecimento e distribuição, ou seja, é necessário implementar as boas práticas em todas as etapas da produção dos alimentos: antes, dentro e fora da porteira. A adoção de soluções eficientes ao longo da cadeia produtiva viabiliza a chegada do alimento produzido até o consumidor final, com a diminuição de perdas e desperdícios, sendo uma das formas de garantir segurança alimentar e nutricional (SEBRAE, 2016; FAO, 2011).

Atualmente, a esfera global passa por processos transformatórios no atendimento aos clientes, devido à pandemia que se instaurou de forma gradativa. Antes dessa situação mundial, os consumidores já buscavam novas formas de compra por alimentos com qualidade nutritiva, boa aparência e seguros, além da busca por empresas que adotassem práticas sustentáveis e que fariam a comercialização por delivery. Portanto, o objetivo neste trabalho foi avaliar o nicho do mercado de entregas a domicílio para frutas e hortaliças dos hortifrútis, focando na qualidade e segurança dos alimentos, em Campos dos Goytacazes, município do interior do Estado do Rio de Janeiro.

\section{Material e Métodos}

O trabalho foi realizado no município de Campos dos Goytacazes - RJ, no período de outubro a novembro de 2019, pré-pandemia do coronavírus SARS-CoV-2, em 10 hortifrútis diferentes que realizam o serviço de entregas a domicílio (delivery). O trabalho foi fundamentado nas três seguintes avaliações:

- Avaliação da entrega a domicílio (delivery) nos hortifrútis

A primeira avaliação foi relacionada às vantagens e desvantagens do nicho de mercado de entregas a domicílio, por meio de pesquisa de campo exploratória e descritiva nos estabelecimentos de hortifrútis e entrevista estruturada. As entrevistas foram realizadas com os responsáveis pelo empreendimento, setor de hortofrutícolas e entregas (Quadro 1).

Quadro 1. Perguntas da entrevista estruturada com os responsáveis nos hortifrútis.

\begin{tabular}{|l|l|}
\hline 1- São produtores? & ( ) Sim $\quad$ ( ) Não \\
\hline 2- Quem são os fornecedores das frutas? \\
\hline 3- Quem são os fornecedores das hortaliças? \\
\hline $\begin{array}{l}\text { 4- Vende produtos minimamente processados? } \\
\text { Se sim, quem prepara os minimamente processados? }\end{array}$ \\
\hline 5- Quantos funcionários tem o estabelecimento? E suas funções? \\
\hline
\end{tabular}


6- Quais as condições higiênico-sanitárias da loja física?

Aplicação de alguns itens do checklist da RDC 216/2004 (Anvisa).

7- Como é o armazenamento/estoque dos produtos?

8- São todos os produtos que são entregues a domicílio? Quais são?

9- Quais os critérios que utilizam para a escolha dos produtos entregues a domicílio?

10- Como é a embalagem dos produtos entregues a domicílio?

11- Como são transportados os produtos do serviço de entrega a domicílio?

12- Quais estratégias de marketing (divulgação) que utilizam?

13- Quais técnicas de gestão utilizam para administrar o empreendimento?

14- Quais são os custos operacionais da loja física?

15- Quais são os custos da entrega a domicílio?

16- Realizam algum tipo de controle de receitas e despesas?

17- E as vendas a domicílio apresentaram algum incremento na renda mensal?

Fonte: Própria (2020).

Ao todo foram 10 hortifrútis de Campos dos Goytacazes, distribuídos pelos seguintes bairros do município: Parque (Pq.) Aldeia (Guarus), Pecuária, Pq. Leopoldina, Pq. Califórnia, Pq. Aurora, IPS, Centro, Pq. Santo Amaro, Turf Club, Pq. Imperial e Penha. O processo de seleção desses hortifrútis foi por meio das redes sociais (Instagram e Facebook) que utilizam como principal meio de divulgação do serviço de entrega no município.

O intuito da entrevista estruturada foi caracterizar esses estabelecimentos quanto aos fornecedores de frutas e hortaliças, o número de funcionários, as condições higiênico-sanitárias (da loja física, do armazenamento e do transporte), os critérios para a escolha dos produtos, avaliar as estratégias de marketing e de gestão empregadas para administração do empreendimento.

- Avaliação das condições higiênico-sanitárias nos hortifrútis

A segunda avaliação foi das condições higiênico-sanitárias das lojas físicas dos hortifrútis que foram avaliadas de acordo com as boas práticas de manipulação, realizadas no setor de hortofrutícolas com aplicação de alguns itens do checklist fundamentado na RDC $\mathrm{N}^{\circ}$ 216/2004 (ANVISA), apresentado abaixo no Quadro 2.

Quadro 2. Itens do checklist, baseado na RDC No 216/2004 (ANVISA), aplicado nos hortifrútis de Campos dos Goytacazes/RJ. Perguntas cuja resposta é "SIM", marcou-se quando o estabelecimento atende ao item, "NÃO", quando o estabelecimento não atende ao item e "NA" 
(não se aplica), quando o estabelecimento não possui este setor ou esta operação.

\section{EXPOSIÇÃO AO CONSUMO E ORGANIZAÇÃO}

1) Higiene: As áreas de exposição do alimento (gôndolas e balcões refrigerados) são mantidas organizadas e em adequadas condições higiênicosanitárias (limpas e livres de contaminação)?

2) Os equipamentos necessários à exposição ou distribuição dos alimentos minimamente processados, sob temperaturas controladas, são devidamente dimensionados e estão em adequado estado de higiene, conservação e funcionamento?

3) PEPS (Primeiro a Entrar, Primeiro a Sair): as mercadorias mais antigas estão sobre as novas?

4) Os códigos de rastreabilidade estão funcionando?

\section{MATÉRIAS-PRIMAS, INGREDIENTES E EMBALAGENS}

1) Integridade das embalagens primárias: ausência de rasgos, furos, bem como aquelas que apresentem sujidades que possam alterar a qualidade e integridade do produto?

2) A temperatura das matérias-primas e ingredientes que necessitem de condições especiais de conservação está adequada?

3) Estão adequadamente acondicionados e identificados com o prazo de validade?

4) Para os alimentos dispensados da obrigatoriedade da indicação do prazo de validade, é observada a ordem de entrada dos mesmos?

5) Os produtos com prazos de validade vencidos são retirados diariamente da área de venda, descartados ou separados e identificados para troca?

6) Os alimentos consumidos crus são submetidos a algum processo de higienização, a fim de reduzir a contaminação superficial?

7) Os produtos minimamente processados têm as seguintes informações: identificação do produto, nome da marca, quantidade, ingredientes, preço, data de fabricação e data ou prazo de validade?

\section{QUALIDADE DOS PRODUTOS}

1) Defeito leve

2) Defeito grave

3) Estágio de maturação

4) Podridão

\section{MANIPULADORES}

1) Verifica-se que os manipuladores adotam procedimentos que minimizem o risco de contaminação dos alimentos preparados por meio da antissepsia das mãos e pelo uso de utensílios ou luvas descartáveis? 


\begin{tabular}{|c|c|c|c|}
\hline $\begin{array}{l}\text { 2) Os manipuladores possuem higiene pessoal, apresentando-se com } \\
\text { uniformes compatíveis à atividade, conservados e limpos? }\end{array}$ & & & \\
\hline $\begin{array}{l}\text { 3) Os manipuladores usam cabelos presos e protegidos por redes, toucas ou } \\
\text { outro acessório apropriado para esse fim, não sendo permitido o uso de barba } \\
\text { nem adornos? }\end{array}$ & & & \\
\hline V. ABASTECIMENTO DE ÁGUA & SIM & NÃO & NA \\
\hline 1) É utilizada somente água potável para higienização das FVL? & & & \\
\hline $\begin{array}{l}\text { 2) Quando utilizada solução alternativa ao abastecimento de água pública, a } \\
\text { potabilidade é atestada semestralmente mediante laudos laboratoriais? }\end{array}$ & & & \\
\hline $\begin{array}{l}\text { 3) O reservatório de água é edificado e ou revestido de materiais que não } \\
\text { comprometam a qualidade da água? }\end{array}$ & & & \\
\hline $\begin{array}{l}\text { 4) O reservatório de água é higienizado em um intervalo máximo de seis } \\
\text { meses? }\end{array}$ & & & \\
\hline $\begin{array}{l}\text { 5) São mantidos registros da operação de higienização do reservatório de } \\
\text { água? }\end{array}$ & & & \\
\hline VI. INSTALAÇÕES FÍSICAS & SIM & NÃO & NA \\
\hline $\begin{array}{l}\text { 1) As áreas internas e externas do estabelecimento estão livres de objetos em } \\
\text { desuso ou estranhos ao ambiente? }\end{array}$ & & & \\
\hline $\begin{array}{l}\text { 2) As instalações são mantidas íntegras, conservadas, livres de rachaduras, } \\
\text { trincas, goteiras, vazamentos, infiltrações, bolores, descascamentos? }\end{array}$ & & & \\
\hline $\begin{array}{l}\text { 3) As instalações físicas como piso, parede e teto possuem revestimento liso, } \\
\text { impermeável e lavável? }\end{array}$ & & & \\
\hline $\begin{array}{l}\text { 4) As instalações são abastecidas com água tratada e dispõem de conexões } \\
\text { com rede de esgoto público ou fossa séptica? }\end{array}$ & & & \\
\hline $\begin{array}{l}\text { 5) As portas da área de preparação e armazenamento de alimentos são dotadas } \\
\text { de fechamento automático? }\end{array}$ & & & \\
\hline $\begin{array}{l}\text { 6) As aberturas externas das áreas de armazenamento e preparação de } \\
\text { alimentos, inclusive o sistema de exaustão, são providas de telas milimetradas } \\
\text { para impedir o acesso de vetores e pragas? }\end{array}$ & & & \\
\hline 7) As telas são removíveis para facilitar a limpeza periódica? & & & \\
\hline $\begin{array}{l}\text { 8) Os ralos são sifonados e as grelhas possuem dispositivo que permitam seu } \\
\text { fechamento? }\end{array}$ & & & \\
\hline VII. ARMAZENAMENTO E TRANSPORTE DOS ALIMENTOS & SIM & NÃO & NA \\
\hline $\begin{array}{l}\text { 1) As matérias-primas, os ingredientes e as embalagens são armazenados } \\
\text { respeitando-se o espaçamento mínimo necessário para garantir adequada } \\
\text { ventilação e limpeza e, quando for o caso, desinfecção do local? }\end{array}$ & & & \\
\hline $\begin{array}{l}\text { 2) Os paletes, estrados e prateleiras são de material liso, resistente, } \\
\text { impermeável e lavável? }\end{array}$ & & & \\
\hline $\begin{array}{l}\text { 3) Os alimentos preparados aguardando o transporte estão organizados, } \\
\text { identificados e protegidos contra contaminantes? }\end{array}$ & & & \\
\hline
\end{tabular}


4) O armazenamento e o transporte do alimento preparado, da distribuição até a entrega ao consumo, ocorrem em condições de tempo e temperatura que não comprometam sua qualidade higiênico-sanitária?

5) Os meios de transporte do alimento preparado são higienizados, sendo adotadas medidas a fim de garantir a ausência de vetores e pragas?

6) Os veículos são dotados de cobertura para proteção da carga, não transportando outras cargas que comprometam a qualidade higiênico-sanitária do alimento preparado?

Fonte: Adaptado de Brasil (2004).

- Avaliação do perfil e da satisfação dos consumidores finais

A terceira avaliação do trabalho foi baseada nos perfis e na satisfação dos consumidores finais dos hortifrútis, com a finalidade de verificar os seguintes parâmetros: idade, renda, escolaridade, frequência de compra de entrega a domicílio, avaliação do atendimento e da qualidade dos produtos alimentícios comercializados, se retornaria ao estabelecimento para novas compras e a fazer uso do serviço de delivery. Essa pesquisa de satisfação foi realizada de forma indireta, voluntária e aberta para os clientes dos hortifrútis, por meio de questionários, divulgados pelos canais de comunicação e-mail e WhatsApp, a fim de garantir um público-alvo de 50 consumidores. Foi utilizada a plataforma do Google Forms para a elaboração do questionário (Quadro 3) e suas ferramentas para formulação dos gráficos com auxílio do Excel, a partir dos dados obtidos pelas respostas dos consumidores, e assim foram analisadas e discutidas.

Quadro 3. Questionário aplicado em Campos dos Goytacazes/RJ para avaliar o perfil e a satisfação dos consumidores finais do serviço de delivery dos hortifrútis.

\section{Questionário do perfil e da satisfação dos consumidores-clientes}

Esse questionário faz parte de uma pesquisa para avaliar o perfil dos consumidores e a satisfação do serviço de entrega a domicílio de frutas, legumes e verduras em Campos dos Goytacazes - RJ com o intuito da melhoria desse serviço e da qualidade dos produtos comercializados. Desde já agradeço a colaboração!

*Obrigatório

1. Idade?*

2. Renda? * (Marcar apenas uma).

Até 1 salário mínimo.

1 a 2 salários mínimos. 
3 a 4 salários mínimos.

Acima de 4 salários mínimos.

3. Escolaridade? * (Marcar apenas uma).

Ensino fundamental.

Ensino Médio.

Ensino Técnico.

Ensino Superior.

Sem escolaridade.

4. Qual é a frequência que você realiza a compra com entrega a domicílio? * (Marcar apenas uma).

É a primeira vez que compro.

Uma vez na semana.

Mais de uma vez na semana.

Mais de duas vezes no mês.

Outro:

5. Como foi o atendimento por telefone ou por WhatsApp ou pela rede social? * (Marcar apenas uma).

Ótimo.

Bom

Regular.

Ruim.

Outro: 
6. Qual foi a qualidade dos produtos alimentícios que chegaram na sua casa? * (Marcar apenas uma).
Ótima.
Boa.
Regular.
Ruim.
Outro:

7. Quais aspectos influenciaram na avaliação da qualidade dos produtos? *

(Pode selecionar mais de uma opção. Marque todas que se aplicam).

Aparência.

Limpeza.

Armazenamento.

Embalagem.

Outro:

8. O que te agradou no serviço de entrega a domicílio? *

(Pode selecionar mais de uma opção. Marque todas que se aplicam.)

Produtos de qualidade.

Bom atendimento.

Preço.

Comodidade.

Praticidade.

Economia de tempo.

Outro: 


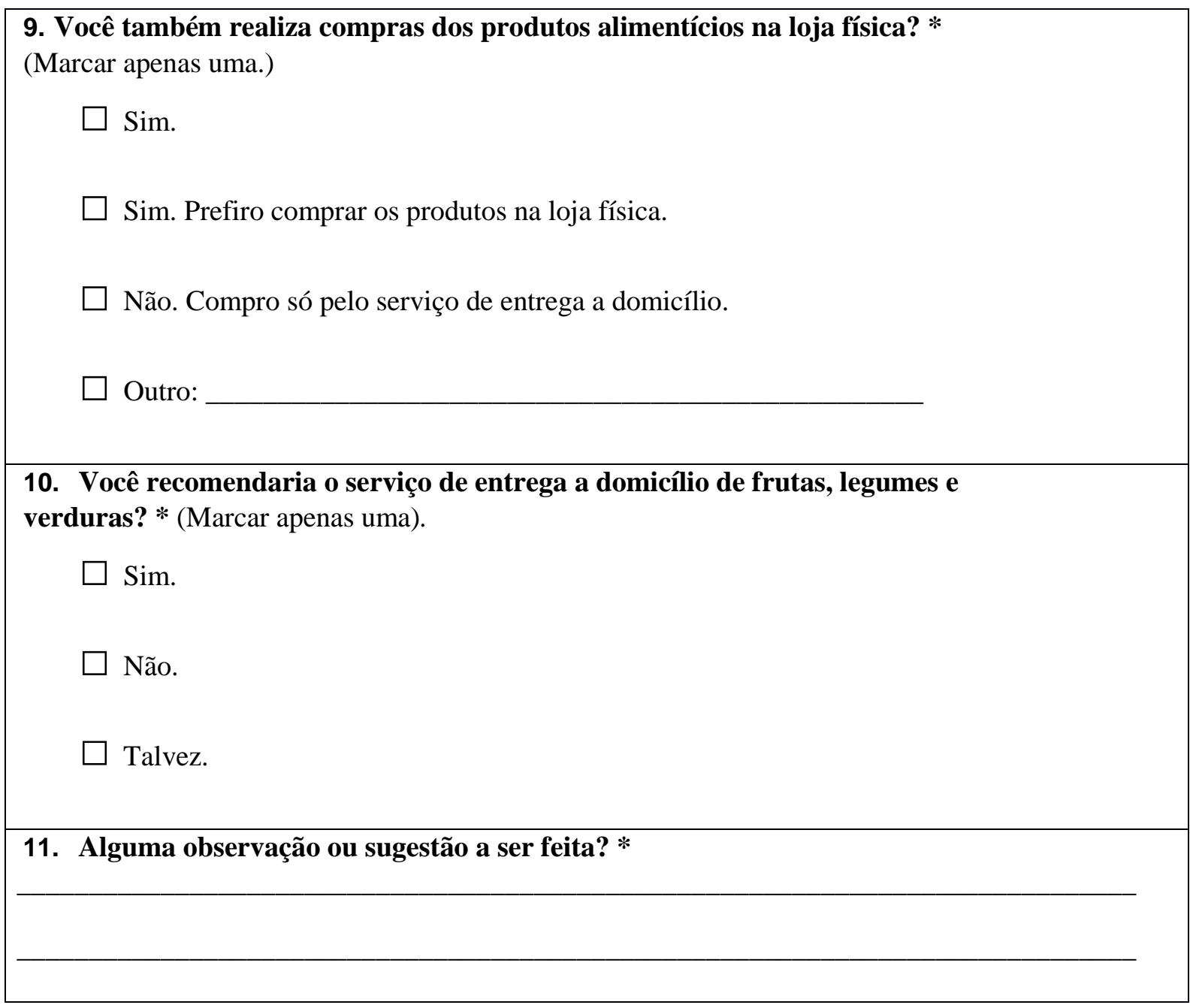

Fonte: Própria (2020).

\section{Resultados e Discussão}

- Avaliação da entrega a domicílio (delivery) nos hortifrútis

As redes sociais (Instagram e Facebook) e o WhatsApp são os principais meios de divulgação e marketing que os hortifrútis utilizam para expor seus produtos e receber os pedidos do serviço de entrega em Campos dos Goytacazes/RJ. Além de contar com a colaboração de influenciadores, clientes e parceiros na divulgação. Um desses hortifrútis utiliza um aplicativo gratuito para smartphones e um site exclusivo para atender aos pedidos do serviço de entregas a domicílio.

De todos os hortifrútis visitados, que realizam o serviço de entrega a domicílio, apenas um estabelecimento produz as hortaliças que comercializa. No qual o trabalho é realizado em uma escola estadual de Campos dos Goytacazes, ou seja, é um trabalho educativo, pedagógico e motivador para os alunos. Os envolvidos no trabalho são os próprios professores, da área técnica agropecuária, alunos, do ensino médio e do técnico em agropecuária, e a vice-diretora 
da escola, que é a responsável pela entrega dos produtos. A formulação do preço das hortaliças é feita de acordo com uma avaliação da cotação da semana do Ceasa/RJ das matérias-primas, além de avaliar o preço no mercado local e acrescenta em 30\% de valor agregado. Não há um retorno financeiro diretamente para os colaboradores. O dinheiro arrecadado é para financiar as produções, os custos operacionais (compra dos insumos, combustível, embalagens) e alguns momentos de lazer com os alunos (lanches).

Os demais hortifrútis compram as frutas e hortaliças de fornecedores. Os fornecedores das frutas são de pequenos produtores de Campos dos Goytacazes, São Francisco de Itabapoana, Rio de Janeiro e de Vitória (ES). Os fornecedores de hortaliças são de pequenos produtores de Campos dos Goytacazes, São Francisco de Itabapoana, São João da Barra, Rio de Janeiro, da região serrana (Nova Friburgo e Teresópolis) e de Vitória (ES). Os produtos chegam 3 vezes por semana ou todo dia, dependendo da sua origem.

Nem todos os hortifrútis visitados apresentaram setor de armazenamento das frutas e hortaliças. Estas chegam dos fornecedores e já vão direto para a exposição à venda. Apenas 3 hortifrútis apresentaram câmaras frias, com temperaturas controladas, para armazenamento dos produtos. Um hortifrúti que só faz a entrega a domicílio, ao receber os produtos já separa os pedidos para ser entregue posteriormente. A escola utiliza uma sala como o local de recepção para dispor as hortaliças coletadas. Durante a colheita das hortaliças, eles tentam ao máximo não deixar resíduos de terra. As hortaliças ficam nessa sala até o momento de entrega. Os tomates são embalados em bandejas de isopor cobertos com filme PVC. Os pedidos são separados e as hortaliças são acondicionadas em cestas de papelão limpas e reaproveitadas (caixas de achocolatado que a escola recebe). Vale lembrar que este tipo de embalagem reaproveitada (papelão) tem que ser higienizada corretamente antes de acondicionar as frutas e hortaliças para evitar o risco de contaminação cruzada. Todos os outros hortifrútis utilizam sacolas ou caixas plásticas ao entregar os produtos a domicílio.

O excedente da produção de tomate e dos temperos verdes da escola é empregado na produção de molho de tomate, que também é comercializado. Outros excedentes das demais hortaliças são distribuídos para o consumo na residência dos seus alunos ou são utilizadas na compostagem para adubação das hortas na escola. Os tomates e os temperos verdes selecionados na quitanda e são separados para serem processados, a fim de obter o molho. Se eles realizam a produção de molho de tomate no mesmo dia da coleta, eles direcionam os produtos para o laboratório de processamento da escola para realizar as etapas de sanitização, preparação e acondicionamento do molho. Entretanto, caso eles não realizem a produção no dia da colheita, as hortaliças são armazenadas sob refrigeração. Essas formas de diversificar a 
produção e seus produtos tem o intuito de minimizar as perdas e desperdícios dos alimentos, além de aumentar as alternativas de comercialização e renda (SEBRAE, 2016; FAO, 2011).

Os hortifrútis comercializam os produtos minimamente processados. Porém, apenas a escola, entre os estabelecimentos avaliados, que é responsável pela produção e comercialização desses produtos, como quiabo, milho, couve, coco, alho descascado e tomate. Os pequenos estabelecimentos (7 unidades), que correspondem $70 \%$ dos hortifrútis avaliados, apenas fazem uma limpeza superficial, cortam pela metade e embalam com filme de PVC, tais como abóbora, melancia, melão e mamão. Os estabelecimentos maiores (3 unidades), que representam 30\% dos hortifrútis avaliados, apresentaram uma cozinha e fazem limpeza, sanitização e acondicionamento.

Todos os produtos dos hortifrútis são comercializados nos serviços de entregas a domicílio. O critério que os hortifrútis utilizam para escolha dos produtos é a melhor qualidade do produto e varia de acordo com a demanda do consumidor final. Vale lembrar que 2 estabelecimentos realizam a entrega a domicílio em dias específicos, posterior a data de chegada dos produtos dos fornecedores, para garantir a qualidade (estado de frescor) dos mesmos. Os demais hortifrútis atendem no horário comercial, respeitando o horário de almoço. Outro critério que utilizaram para o serviço de entregas a domicílio é a taxa mínima de compras para realizar a entrega ou taxa fixa de entrega (1 hortifrúti).

Uma vez que muitos dos hortifrútis são localizados em bairros, a bicicleta é o meio de transporte utilizado em quase todos os estabelecimentos, devido ao menor custo operacional. Já quando a entrega é para outro bairro mais distante, pode ser utilizado uma moto ou um carro ou uma Kombi, como já mencionado. Um estabelecimento só realiza entregas, já que não tem loja física, e só utiliza o carro, a fim de manter a qualidade dos produtos e atender a sua clientela.

Quanto à gestão do empreendimento, todos os hortifrútis relataram que fazem o controle de receitas e despesas pelo fluxo de caixa diariamente, semanalmente e mensalmente. Focam no controle de perdas e tentam ao máximo reduzi-las. Os estabelecimentos maiores, $30 \%$ dos hortifrútis avaliados, realizam treinamentos da equipe e avaliação de produtividade, o que motiva os colaboradores. Quase todos os hortifrútis, com exceção da escola e do estabelecimento que só faz a entrega, relataram que os custos operacionais da loja física inviabilizam a manutenção desta estrutura, por exemplo, as contas de aluguel, água, luz, folha de pagamento dos funcionários, impostos e fornecedores.

Os custos da escola são água, luz, insumos, instrumentos e equipamentos para colheita e processamento. Enquanto, os custos operacionais da entrega a domicílio dos hortifrútis são: manutenção do veículo, combustível e funcionário. No caso do hortifrúti que só realiza as 
entregas a domicílio, além dos custos operacionais da entrega, tem o custo do aluguel da banca que é utilizada como suporte quando chegam os produtos dos fornecedores.

Por fim, 7 estabelecimentos dos hortifrútis visitados (70\%) relataram que a entrega a domicílio proporcionou um incremento na renda mensal, sendo que um destes informou que tal serviço foi tão aceito pela sociedade que abriram mão das vendas presenciais na banca e só atendem pelo serviço de delivery. Os outros 3 estabelecimentos (30\%) alegaram que o serviço agrega valor, porém, atendem algumas vezes por cordialidade e fidelidade aos clientes antigos, mas para eles o lucro é pequeno e, em alguns casos, não é viável.

- Avaliação das condições higiênico-sanitárias nos hortifrútis

Em relação às condições higiênico-sanitárias analisadas pelas boas práticas de manipulação das frutas e hortaliças, segue abaixo a Tabela 1 que apresenta os resultados do checklist com os itens avaliados nos 10 hortifrútis.

Tabela 1. Itens do checklist da RDC 216 avaliados nos 10 hortifrútis

\begin{tabular}{lccc}
\hline \multicolumn{1}{c}{ CHECKLIST RDC 216 DE 2004 (ANVISA) } & SIM (\%) & NÃO (\%) & NA* (\%) \\
\hline I. Exposição ao consumo e organização & 53,5 & 17,5 & 30,0 \\
II. Matérias-primas, ingredientes e embalagens & 59,0 & 35,0 & 6,0 \\
III. Qualidade dos produtos & 72,5 & 27,5 & 0,0 \\
IV. Manipuladores & 80,0 & 20,0 & 0,0 \\
V. Abastecimento de água & 56,0 & 0,0 & 44,0 \\
VI. Instalações físicas & 47,0 & 26,0 & 26,0 \\
VII. Armazenamento e transporte do Alimento & 82,0 & 5,0 & 13,0 \\
\hline
\end{tabular}

*NA (não se aplica). Fonte: Própria (2020).

Dentre os itens avaliados no checklist (Tabela 1), observa-se que as instalações físicas apresentaram a menor porcentagem de estabelecimentos que atenderam a este item (47\%), principalmente, devido à presença de objetos em desuso e estranhos ao ambiente, limpeza, conservação e revestimentos não laváveis no local. Entretanto, os estabelecimentos atenderam os seguintes itens: $72,5 \%$ da qualidade dos produtos, $80 \%$ dos manipuladores e $82 \%$ no armazenamento e transporte do alimento, o que demonstra uma maior conscientização dos hortifrútis nesses quesitos para garantir a qualidade dos produtos ofertados.

Quanto aos itens de exposição ao consumo e organização (30\%) e abastecimento de água (44\%) dos estabelecimentos de hortifrútis não possuem esse setor (Tabela 1), por se tratar de apenas entrega a domicílio e não ter uma loja física. Os 17,5\% dos estabelecimentos não 
atenderam ao item de exposição ao consumo e organização devido à grande quantidade de produtos expostos de forma desorganizada, às condições de limpeza e ao material das gôndolas inadequadas (sujas e de madeira ou material enferrujado), além de produtos sem os códigos de rastreabilidade.

Dos hortifrútis avaliados, 35\% não atenderam ao item de matérias-primas, ingredientes e embalagens pelo fato de alguns produtos, tais como processados minimamente, estarem fora da temperatura adequada para sua conservação, além de terem sido embalados sem a devida identificação adequada de acordo com a legislação (identificação do produto, nome da marca, quantidade, ingredientes, preço, data de fabricação e data ou prazo de validade).

- Avaliação do perfil e da satisfação dos consumidores finais

De acordo com os resultados do questionário, o perfil dos consumidores do serviço de entrega a domicílio dos hortifrútis em Campos dos Goytacazes varia de 19 a 81 anos, sendo o maior percentual de consumidores na faixa dos 31 a 50 anos (54\%), apenas $14 \%$ na faixa de 51 a 81 anos, e o restante abaixo de 30 anos (32\%). Assim, o público de meia idade está em busca de uma qualidade de vida melhor, no qual representa o grupo de maior consumo de alimentos saudáveis. A Figura 1 apresenta a renda (A) e a escolaridade (B) dos consumidores que utilizam esse serviço dos hortifrútis. Observa-se que a maioria dos consumidores possuem renda acima de 4 salários mínimos (38\%), de 1 a 2 salários (32\%) e tem ensino superior (76\%), apesar de ser um serviço acessível a todos. O nível de escolaridade superior e a renda maior da população representam maior consumo de frutas e hortaliças (GAMA, 2017; IBGE, 2008).

Figura 1. Renda (A) e escolaridade (B) dos consumidores que utilizam o serviço de entrega a domicílio dos hortifrútis em Campos dos Goytacazes - RJ.

A

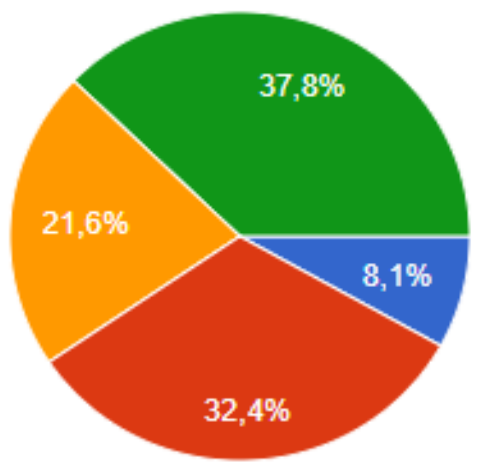

Até 1 salário mínimo

De 1 a 2 salários mínimos

De 3 a 4 salários mínimos

Acima de 4 salários mínimos 
B

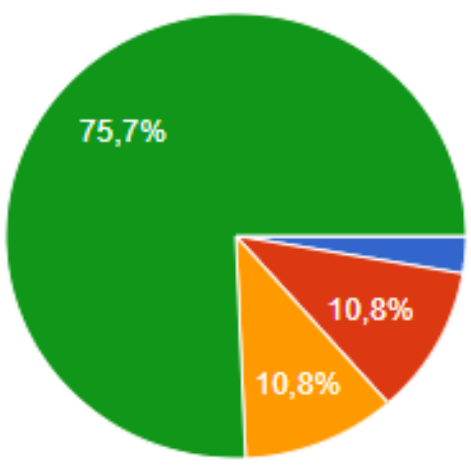

Ensino fundamental.

Ensino Médio.

Ensino Técnico.

Ensino Superior.

Sem escolaridade.

Fonte: Própria (2020).

Os resultados mostraram que os consumidores estão satisfeitos com a qualidade no atendimento ao cliente oferecida por todos os meios utilizados pelos hortifrútis (telefone, site e rede social), sendo classificados como ótimo (46\%) e bom (37\%). No entanto, $17 \%$ dos consumidores classificaram como regular e as observações que eles citaram foram a demora em responder no WhatsApp. Provavelmente, por conta de falhas no sinal de internet ou indisponibilidade de pronto atendimento por parte dos colaboradores. Quando entravam em contato por via telefônica com o hortifrúti, eram informados que não poderiam receber o pedido, pois estavam em atendimento a outros clientes. Além disso, alguns consumidores alegaram que poderia ter um aviso prévio sobre a indisponibilidade de certos produtos, pois, do contrário, eles só sabem que não existe o produto disponível quando as compras são entregues.

Dessa forma, a sugestão dos consumidores seria disponibilização de uma lista com todos os produtos ofertados e seus respectivos preços, permitindo uma decisão de compra adequada às necessidades dos clientes ou o envio de fotos dos produtos aos clientes antes da entrega a domicílio. Como também não enviar áudios, pois muitos consumidores não conseguem escutar no mesmo tempo e demoram responder prontamente a solicitação, o que dificulta a finalização do pedido das compras.

Os resultados da frequência dos consumidores, que realizam a compra pelo serviço de entrega a domicílios nos hortifrútis (Figura 2), mostraram que eles estão sempre adquirindo os produtos por esse serviço, o que evidencia a fidelidade desses clientes. Já que: $43 \%$ compram semanalmente, $30 \%$ mais de duas vezes no mês, $20 \%$ compraram pela primeira vez e $5 \%$ realizam a compra mais de uma vez na semana. A frequência de compras de hortifrútis está relacionada ao consumo de alimentos mais saudáveis (HORTIFRUTI BRASIL, 2019; GAMA, 2017). 
Figura 2. Frequência dos consumidores na compra de entrega a domicílio nos hortifrútis em Campos dos Goytacazes - RJ.

\section{Frequência de compras delivery}

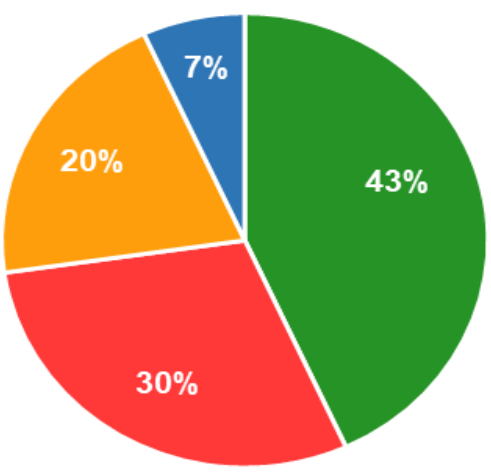

- Semanalmente

- Mais de duas vezes no mês

- É a primeira vez que compro

- Mais de uma vez na semana

Fonte: Própria (2020).

A qualidade dos produtos entregues a domicílio vem sendo satisfatória pela maioria dos consumidores, em vista de que classificaram a qualidade como boa (50\%) e ótima (41\%). Entretanto, apenas 9\% dos consumidores classificaram a qualidade dos produtos entregues como regular, possivelmente pelos aspectos avaliados (embalagem, armazenamento, limpeza e aparência). Os quais foram todos selecionados pelos consumidores (Figura 3). Sendo, a aparência o aspecto de maior relevância na avaliação das frutas e hortaliças pelos $84 \%$ dos consumidores, seguido pelo aspecto da limpeza (64\%). Alguns consumidores alegaram que chegaram a receber produtos com qualidade diferente do que solicitaram e gostariam de saber a origem do produto, o que pode ser evidenciado pela falta da rastreabilidade verificada em alguns produtos dos hortifrútis.

Figura 3. Aspectos da qualidade dos hortifrútis entregues a domicílio em Campos dos Goytacazes - RJ que influenciaram na avaliação dos consumidores.

Quais aspectos influenciaram na avaliação da qualidade dos produtos?

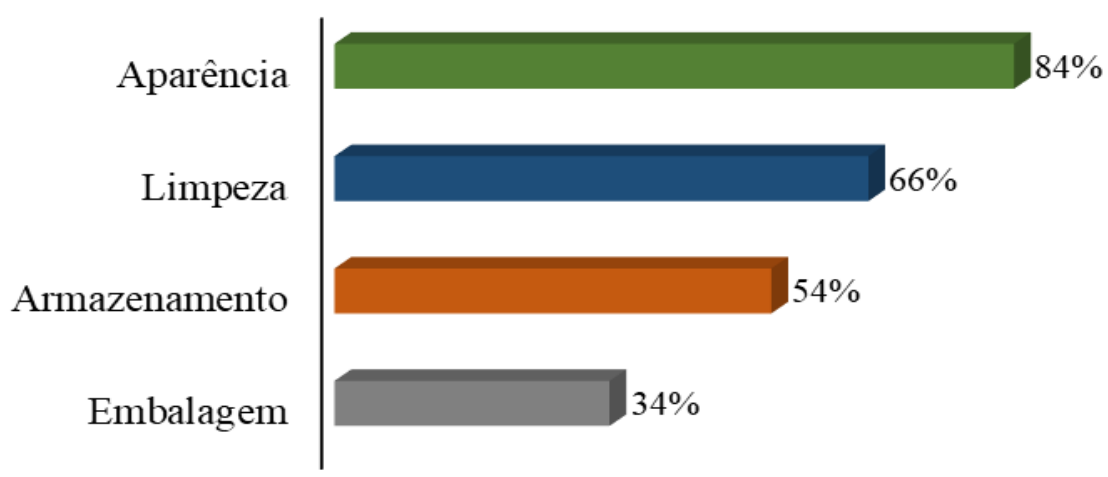

Fonte: Própria (2020). 
Em relação ao serviço de entrega a domicílio dos hortifrútis realizado em Campos dos Goytacazes, antes do aparecimento da COVID-19, 22\% dos consumidores questionados só utilizam o serviço de entrega, $44 \%$ dos consumidores também compram na loja física e $34 \%$ utilizam o serviço de entrega, mas preferem comprar os produtos na loja física. Logo é um serviço que agrega valor aos produtos ofertados nos hortifrútis, sendo um diferencial para o estabelecimento e atraindo, cada vez mais, os consumidores em virtude da qualidade dos produtos e do bom atendimento. Além disso, os consumidores citaram que a comodidade e a praticidade são os fatores que mais agradaram a eles no serviço de entrega a domicílio, principalmente, aqueles que não têm tempo para ir à loja física do hortifrúti e realizar as compras (Figura 4).

Figura 4. Fatores que mais agradaram os consumidores ao utilizar o serviço de entrega a domicílio nos hortifrútis em Campos dos Goytacazes - RJ.

O que te agradou no serviço de entrega?

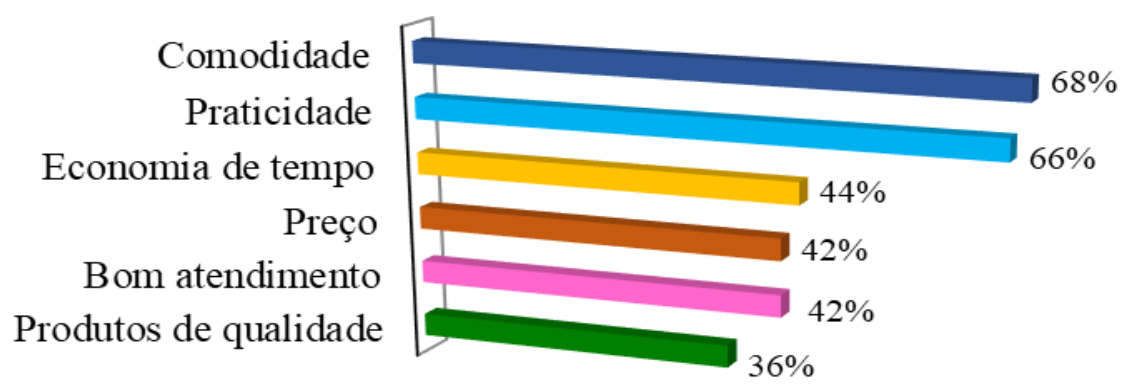

Fonte: Própria (2020).

Por fim, os consumidores ao serem questionados se recomendariam o serviço de entrega a domicílio dos hortifrútis, $80 \%$ dos consumidores responderam que sim, 18\% talvez e apenas $2 \%$ dos consumidores não recomendaram o serviço. Possivelmente, esses consumidores que responderam talvez e não na recomendação, tiveram alguma dificuldade durante a prestação desse serviço. Algumas observações que eles citaram no questionário foram a falta do comprometimento quanto ao tempo de entrega, indisponibilidade de transporte e a quantidade dos produtos, além da sugestão de criar um tipo de pacote fechado com quantidades variadas e pequenas dos produtos ofertados.

É válido ressaltar, que no quadro atual do município com a pandemia ainda existente, há necessidade da realização novamente da pesquisa do perfil e da satisfação dos consumidores pela mesma equipe que realizou esse presente estudo, para fins de constatação do balanço de novas práticas de cuidados com os alimentos com o serviço de delivery. 


\section{Conclusões}

O estudo demonstrou que o serviço de entregas a domicílio para frutas e hortaliças dos hortifrútis, pré-pandemia da COVID-19, em Campos dos Goytacazes, apresentou vantagens em agregar valor aos produtos agrícolas, por ser um diferencial nesse segmento de mercado em crescente expansão, e melhorar a distribuição de renda. Além disso, os consumidores ficaram satisfeitos com o serviço delivery realizado no município, em virtude da qualidade do atendimento e dos produtos ofertados por proporcionar, principalmente, comodidade e praticidade. Uma vez que tecnologias são utilizadas para maximizar os resultados do agronegócio, desde que seja adotado o gerenciamento eficiente dos recursos.

De acordo com a avaliação do checklist, as boas práticas de manipulação dos hortifrútis foram satisfatórias em relação aos itens dos manipuladores, armazenamento e transporte do alimento. Porém, os demais itens precisariam corrigir as inadequações com a implementação do manual de boas práticas para garantir a qualidade e a segurança dos alimentos, conforme as exigências legais vigentes. Mesmo que seja de forma gradativa até tornar os procedimentos operacionais padrões uma rotina.

Sendo assim, esse serviço pode ser considerado uma oportunidade de negócio para produtores rurais locais comercializarem seus produtos do campo diretamente para a mesa do consumidor final, devido à redução dos custos com os intermediários, proprietários das lojas físicas. Uma sugestão seria oferecer um plano básico mensal com entregas semanais de kits padronizados de hortifrútis, entretanto, também poderiam ser oferecidos kits personalizados com preços diferenciados de acordo com a demanda de cada cliente.

\section{Referências}

BRASIL. Agência Nacional de Vigilância Sanitária. Resolução de Diretoria Colegiada (RDC) n. 216 de 15 de setembro de 2004. Aprova o regulamento técnico de boas práticas para serviços de alimentação. Diário Oficial [da República Federativa do Brasil], Brasília, DF, 2004. Disponível em: <http://portal.anvisa.gov.br/documents/10181/2718376/RDC_216 _2004_COMP.pdf/66f5716e-596c-4b9d-b759-72ce49e34da0>. Acesso em: 2 nov. 2019.

CASTRO, MARINELLA. Empreendedores investem no delivery da feira para a mesa do consumidor. 2016. Disponível em: <https://www.em.com.br〉. Acesso em: 4 nov. 2019.

CHITARRA, M. I. F.; CHITARRA, A. B. Pós-colheita de frutos e hortaliças: fisiologia e manuseio. 2. ed. Lavras: Universidade Federal de Lavras, 2005. 785 p. 
FAO. Global food losses and food waste - Extent, causes and prevention. Rome. 2011. Disponível em: <http://www.fao.org/3/a-i2697e.pdf> Acesso em: 4 nov. 2019.

GAMA, MARA. Só $\mathbf{4 0 \%}$ dos brasileiros consomem frutas e hortaliças todo dia. 2017. Disponível em: <https://www1.folha.uol.com.br/mercado/2017/10/1927705-so-40-dosbrasileiros-consomem-frutas-e-hortalicas-todo-dia.shtml>. Acesso em: 1 dez. 2019.

HORTIFRUTI BRASIL. O consumo de frutas não é mais o mesmo! 2019. Disponível em: $<$ https://www.hfbrasil.org.br/br/revista/acessar/completo/edicao-de-marco-quais-tendenciasdevem-nortear-o-consumo-de-frutas.aspx>. Acesso em: 1 dez. 2019.

IBGE. Pesquisa de Orçamento das Famílias. 2008. Disponível em: <https://sidra.ibge.gov.br/pesquisa/pof/tabelas>. Acesso em: 1 dez. 2019.

LIMA, FABIANA DA SILVA. Venda direta como forma de posicionamento estratégico na distribuição de alimentos da produção rural. 2018. 116 f. Dissertação (Mestrado em Agronegócio e Desenvolvimento) - Faculdade de Ciências e Engenharia, Universidade Estadual Paulista "Júlio de Mesquita Filho", Tupã, 2018.

MAGALHÃES, CASA. Supermercado online: saiba porque apostar nesta tendência! Disponível em: <https://www.casamagalhaes.com.br/blog/supermercado-e-varejo/ supermercado-online-saiba-porque-apostar/>. Acesso em: 4 nov. 2018.

SEBRAE. Serviços Delivery. 2014. Disponível em: <http://www.sebraemercados.com.br/wpcontent/uploads/2015/10/2014_07_02_BO_Junho_Servicos_Delivery_validacao.pdf >. Acesso em 4 nov. 2019.

SEBRAE. Fatores-chave de sucesso para a horticultura. Boletim Tendências e Oportunidades. 2016.

SOUZA, ARNON SILLAS NOVAIS; HOLANDA, FRANCISCO SANDRO RODRIGUES. Inovação e modelagem de hortifrútis em Aracajú/SE. Revista Ingi, v. 3, n. 4, p. 503-515, 2019. 